\title{
The Methyl Ether Derivatives of p-tert-Butyl[3.1.3.1]homooxacalixarene. Formation, Structure, and Complexes with Quaternary Ammonium Ions
}

\author{
Bernardo Masci, Stefano Levi Mortera, Daniela Persiani, Pierre Thuéry
}

Dipartimento di Chimica and IMC-CNR, Università "La Sapienza", Box 34 - Roma 62, P.le Aldo Moro 5, 00185 Roma, Italy; CEA/Saclay, SCM (CNRS URA 331), Bât. 125, 91191 Gif-sur-Yvette, France.

\section{Supporting Information}

S2 General methods

S3 Synthesis of compounds 4-6

S4 $\quad{ }^{1} \mathrm{H}$ and ${ }^{13} \mathrm{C}$ NMR spectra of compound 2 in $\mathrm{CDCl}_{3}$ at $298 \mathrm{~K}$.

S5 $\quad{ }^{1} \mathrm{H}$ and ${ }^{13} \mathrm{C}$ NMR spectra of compound 3 in $\mathrm{CDCl}_{3}$ at $298 \mathrm{~K}$.

S6 $\quad{ }^{1} \mathrm{H}$ and ${ }^{13} \mathrm{C}$ NMR spectra of compound 4 in $\mathrm{CDCl}_{3}$ at $298 \mathrm{~K}$.

S7 $\quad{ }^{1} \mathrm{H}$ and ${ }^{13} \mathrm{C}$ NMR spectra of compound 5 in $\mathrm{CDCl}_{3}$ at $298 \mathrm{~K}$.

S8 $\quad{ }^{1} \mathrm{H}$ and ${ }^{13} \mathrm{C}$ NMR spectra of compound 6 in $\mathrm{CDCl}_{3}$ at $298 \mathrm{~K}$.

S9 $\quad{ }^{1} \mathrm{H}$ and ${ }^{13} \mathrm{C}$ NMR spectra of compound 8 in $\mathrm{CDCl}_{2} \mathrm{CDCl}_{2}$ at $350 \mathrm{~K}$.

S10 $\quad{ }^{1} \mathrm{H}$ and ${ }^{13} \mathrm{C}$ NMR spectra of compound 9 in $\mathrm{CDCl}_{3}$ at $298 \mathrm{~K}$.

S11 Figure S1 with low temperature ${ }^{1} \mathrm{H}$ NMR spectra of compound 2

S12 Figure S2 with low temperature ${ }^{1} \mathrm{H}$ NMR spectra of compound $\mathbf{3}$

S13 Figure $\mathrm{S} 3$ with low temperature ${ }^{1} \mathrm{H}$ NMR spectra of compound 5

S14 Figure S4 with low temperature ${ }^{1} \mathrm{H}$ NMR spectra of compound 6

S15 Figure S5 with a complete list of the conformations of compounds 1-7

S16-S18 Crystal structure determination details and structural parameters 


\section{General Methods}

NMR spectra were recorded on a $300 \mathrm{MHz}$ spectrometer, using halogenated solvents $\left(\mathrm{CDCl}_{3}\right.$ if not otherwise indicated) stored on activated $4 \AA$ molecular sieves with TMS as an internal standard. In low temperature ${ }^{1} \mathrm{H}$ NMR measurements, $4 \% \mathrm{CH}_{3} \mathrm{OH}$ in $\mathrm{CD}_{3} \mathrm{OD}$ was used to calibrate the temperature. Mass spectra (ES-MS) were performed by an Electrospray Ionisation Time of Flight spectrometer; negative ion electrospray mass spectra, ES(-) MS were carried out by flow injection analysis in $\mathrm{MeOH}$ of samples in $\mathrm{MeOH} / \mathrm{MeONa}$. Melting points (uncorrected) were obtained in sealed evacuated capillaries. Column chromatography was carried out on 230-400 mesh silica gel. HPLC analyses were performed on a liquid chromatograph fitted with a UV/VIS detector operating at $230 \mathrm{~nm} .$. Samples were analyzed on: Supelcosil LC-18 DB column $(25 \mathrm{~cm} \times 4.6 \mathrm{~mm}$ I.D., particle size $5 \mu \mathrm{m})$; Supelcosil LC-8 DB column $(25 \mathrm{~cm} \times 4.6 \mathrm{~mm}$ I.D., particle size $5 \mu \mathrm{m})$; Supelcosil LC-CN column $(25 \mathrm{~cm} \times 4.6 \mathrm{~mm}$ I.D., particle size $5 \mu \mathrm{m})$; Alltima C18 column ( $25 \mathrm{~cm} \times 4.6 \mathrm{~mm}$ I.D., particle size $5 \mu \mathrm{m}) . \mathrm{MeOH}, \mathrm{MeCN}$ and $\mathrm{MeCN}-\mathrm{H}_{2} \mathrm{O}$ mixtures were used as mobile phases. In no case the peaks of products $\mathbf{2}$ and $\mathbf{4}$ could be satisfactorily separated. 


\section{7,13,21,27-Tetra-tert-butyl-29,31-dihydroxy-30,32-dimethoxy-2,3,16,17-tetrahomo-3,17-}

dioxacalix[4]arene (4). A mixture of 1 (708 mg, $1.00 \mathrm{mmol}), \mathrm{K}_{2} \mathrm{CO}_{3}(690 \mathrm{mg}, 5 \mathrm{mmol})$ and $\mathrm{Me}_{2} \mathrm{SO}_{4}$ (221 $\mathrm{mg}, 1.75 \mathrm{mmol})$ was reacted in acetone $(10 \mathrm{~mL})$ for $8 \mathrm{~h}$. After the usual work-up the residue was recrystallized from acetone to give 4 (378 $\mathrm{mg}, 51 \%)$.

\section{7,13,21,27-Tetra-tert-butyl-29,30-dihydroxy-31,32-dimethoxy-2,3,16,17-tetrahomo-3,17-} dioxacalix[4]arene (5). A mixture of 1 (708 mg, $1.00 \mathrm{mmol}), \mathrm{K}_{2} \mathrm{CO}_{3}(146 \mathrm{mg}, 1.06 \mathrm{mmol})$ and $\mathrm{Me}_{2} \mathrm{SO}_{4}$ (252 $\mathrm{mg}, 2.00 \mathrm{mmol}$ ) was reacted in $\mathrm{MeCN}(8 \mathrm{~mL}$ ) for $1 \mathrm{~h}$. After the usual work-up the residue was recrystallized from $\mathrm{CHCl}_{3} / \mathrm{MeOH}$. The first collected solid $(400 \mathrm{mg})$ consisted of 4 and small amounts of 5 and 2. On further slow solvent evaporation pure 5 was collected (105 mg, 14\%).

\section{7,13,21,27-Tetra-tert-butyl-29-hydroxy-30,31,32-trimethoxy-2,3,16,17-tetrahomo-3,17-}

dioxacalix[4]arene (6). A mixture of $1(1.00 \mathrm{~g}, 1.40 \mathrm{mmol}), \mathrm{K}_{2} \mathrm{CO}_{3}(580 \mathrm{mg}, 4.20 \mathrm{mmol})$ and $\mathrm{Me}_{2} \mathrm{SO}_{4}$ (423 mg, $3.36 \mathrm{mmol})$ was reacted in acetone $(12 \mathrm{~mL})$ for $10 \mathrm{~h}$. After the usual work-up the residue was recrystallized from acetone to give $545 \mathrm{mg}$ of a solid consisting of $\mathbf{4}$ and $\mathbf{7}$. After solvent evaporation from the mother liquors the residue was dissolved in $\mathrm{MeOH}$ and on slow evaporation a second solid (114 mg) consisting of 4, 6 and $\mathbf{7}$ was collected. On further slow evaporation of the mother liquor a third solid was collected, consisting in pure 6 (173 mg, 22\%). 

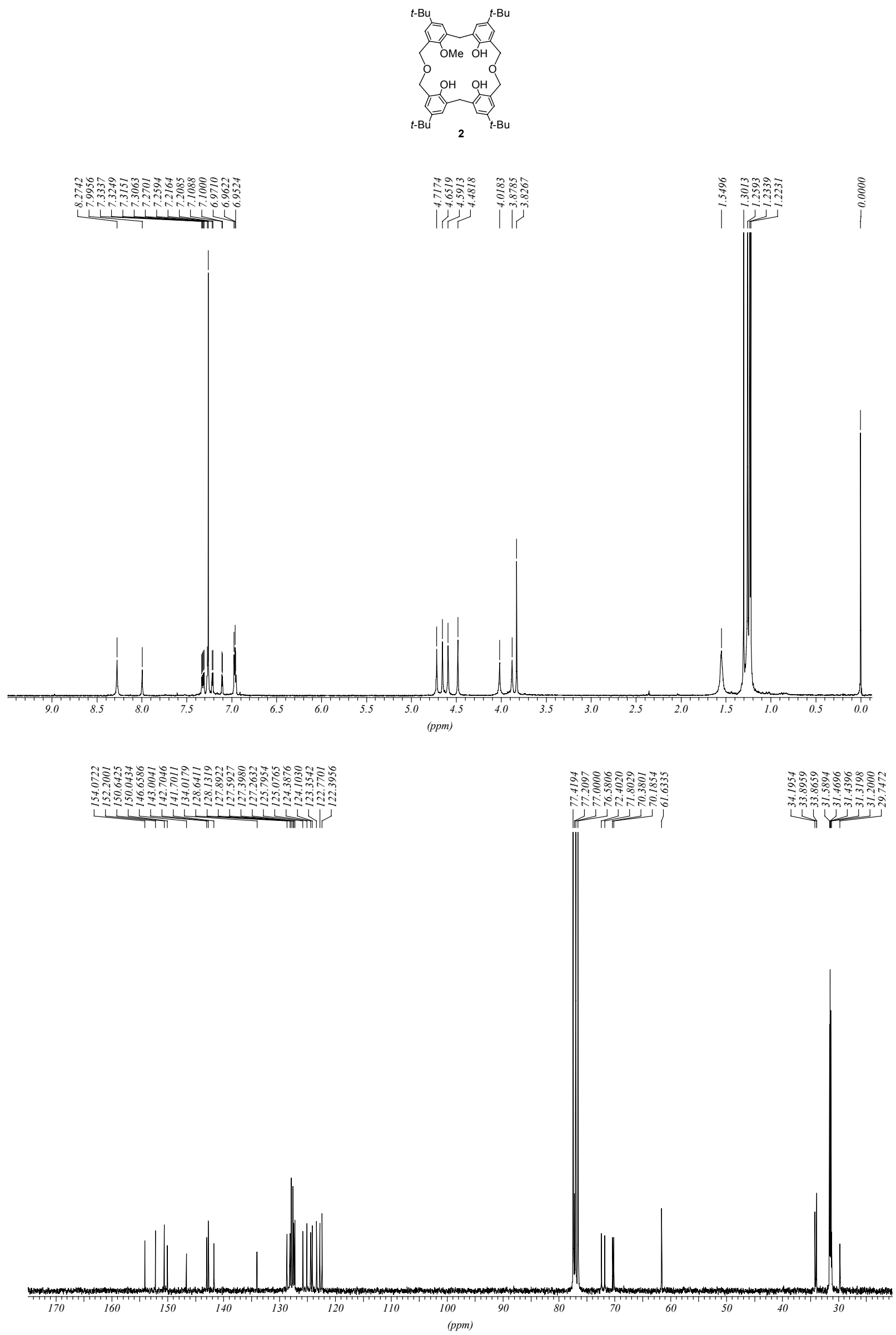


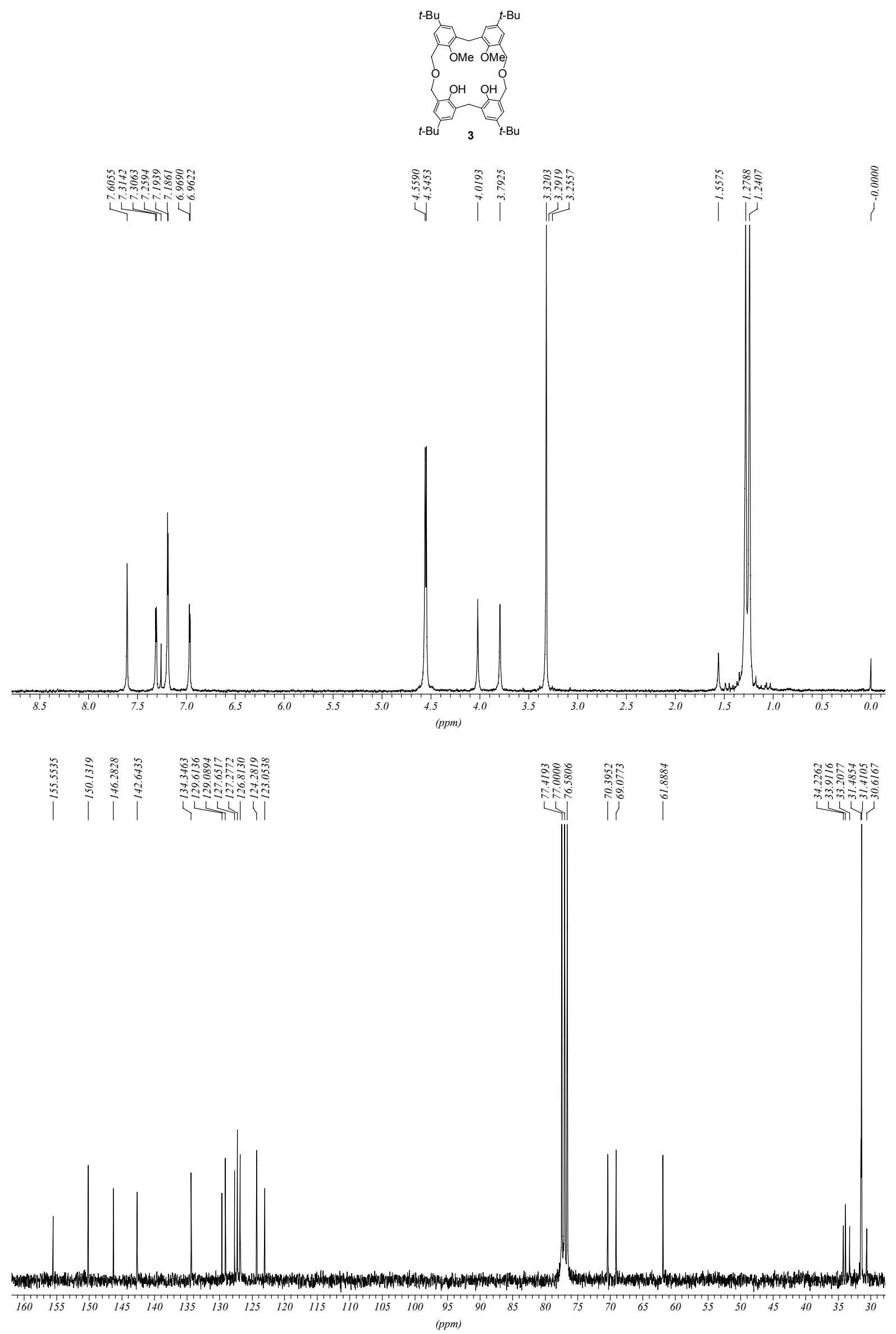




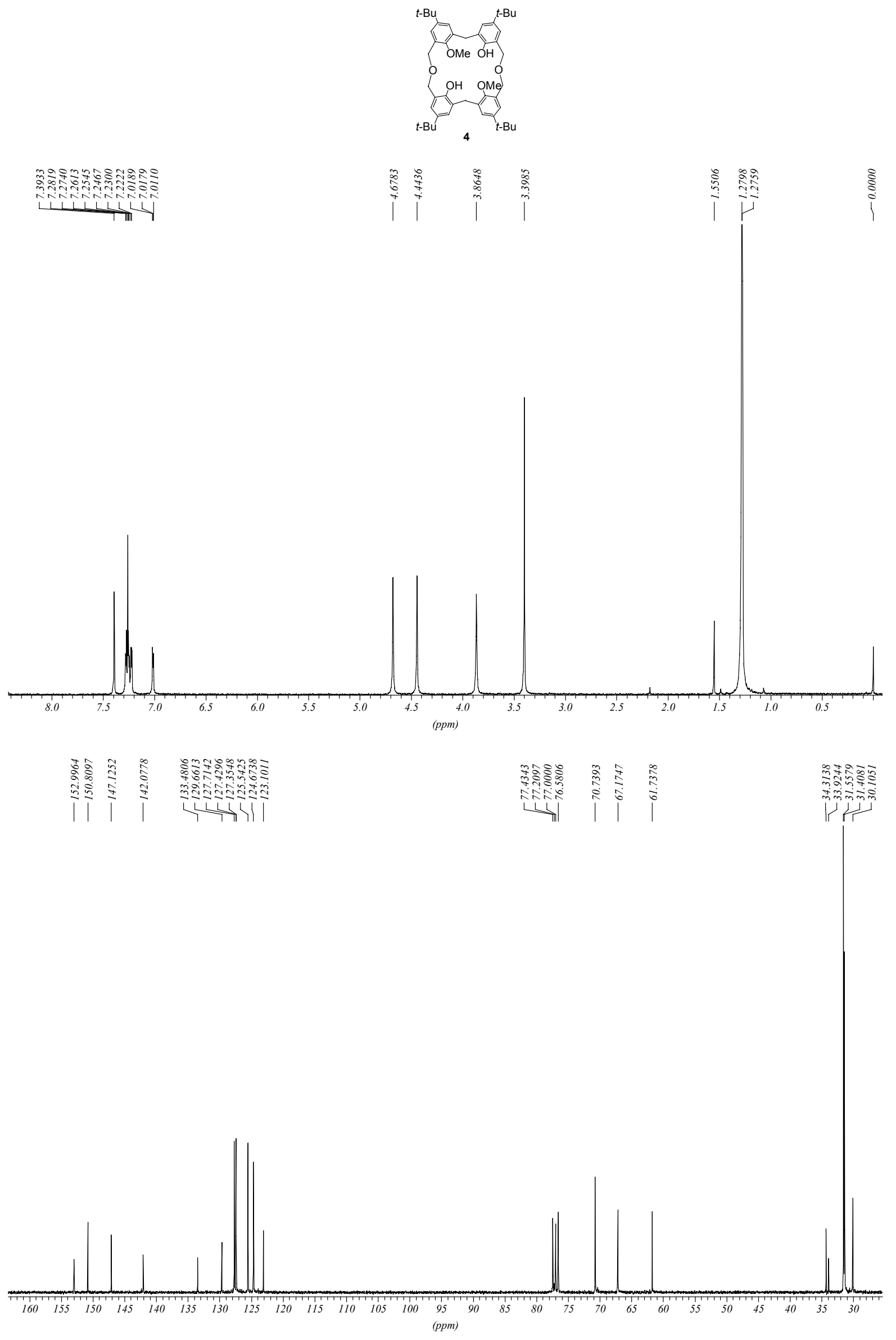




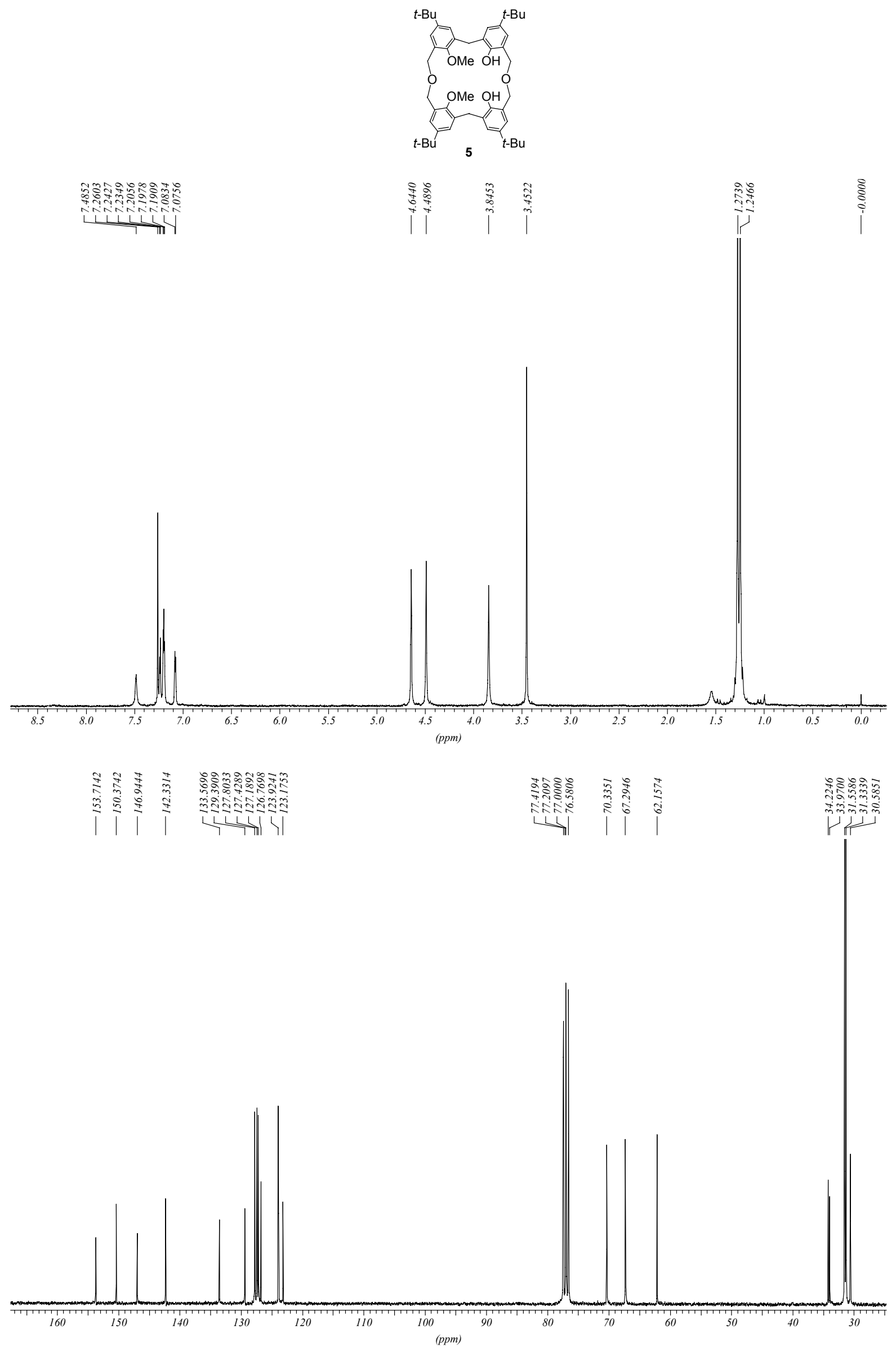




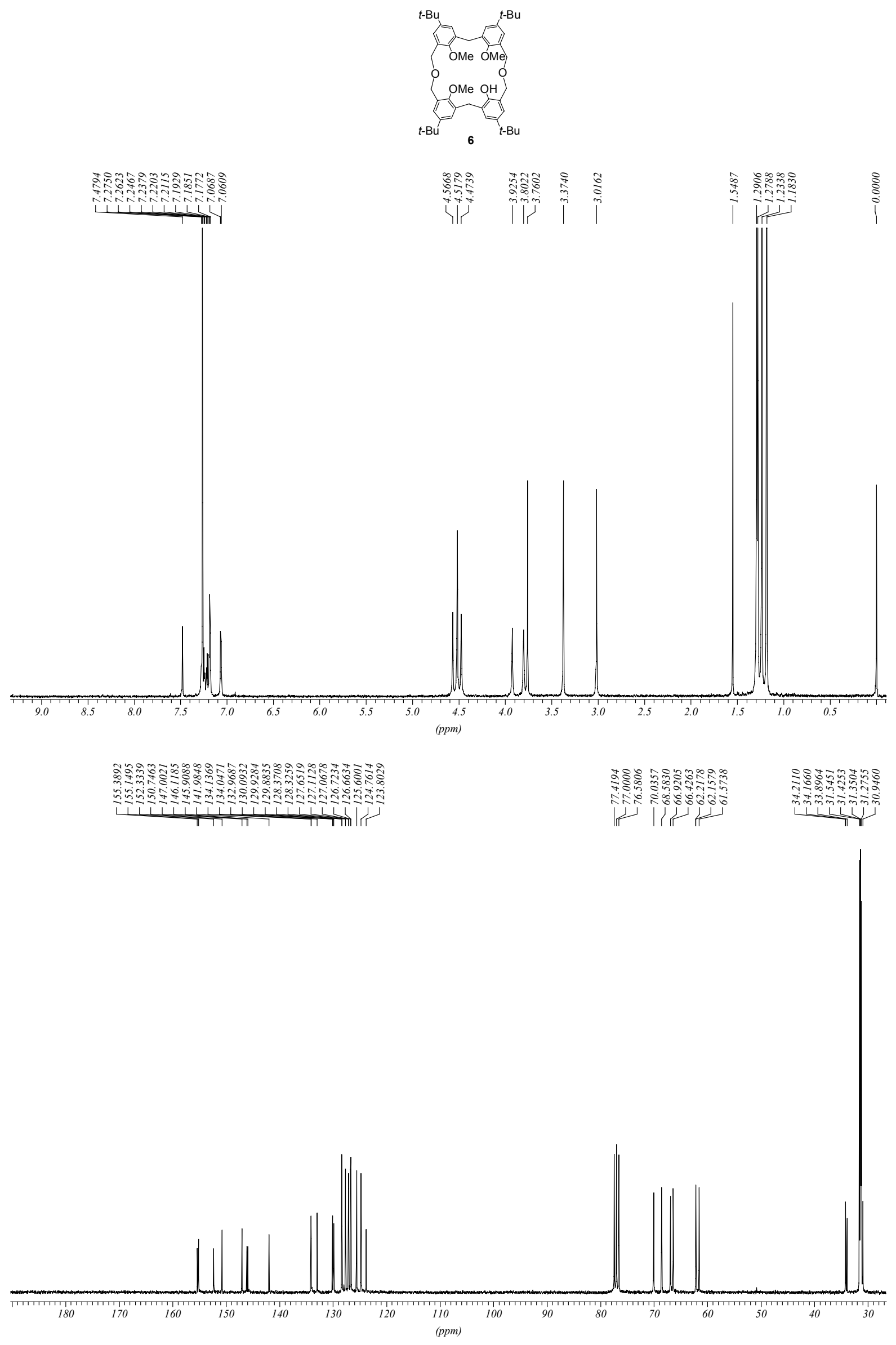



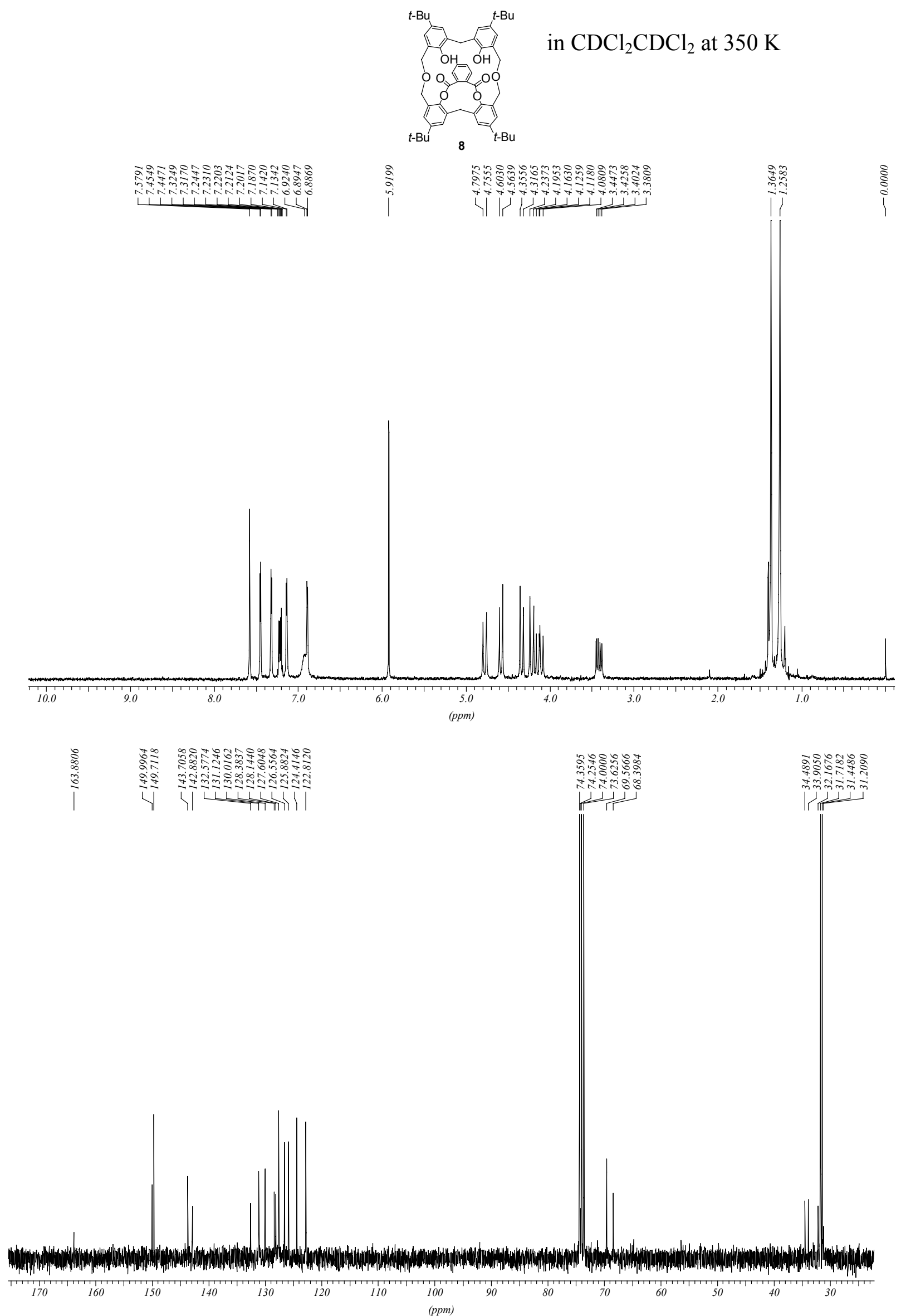

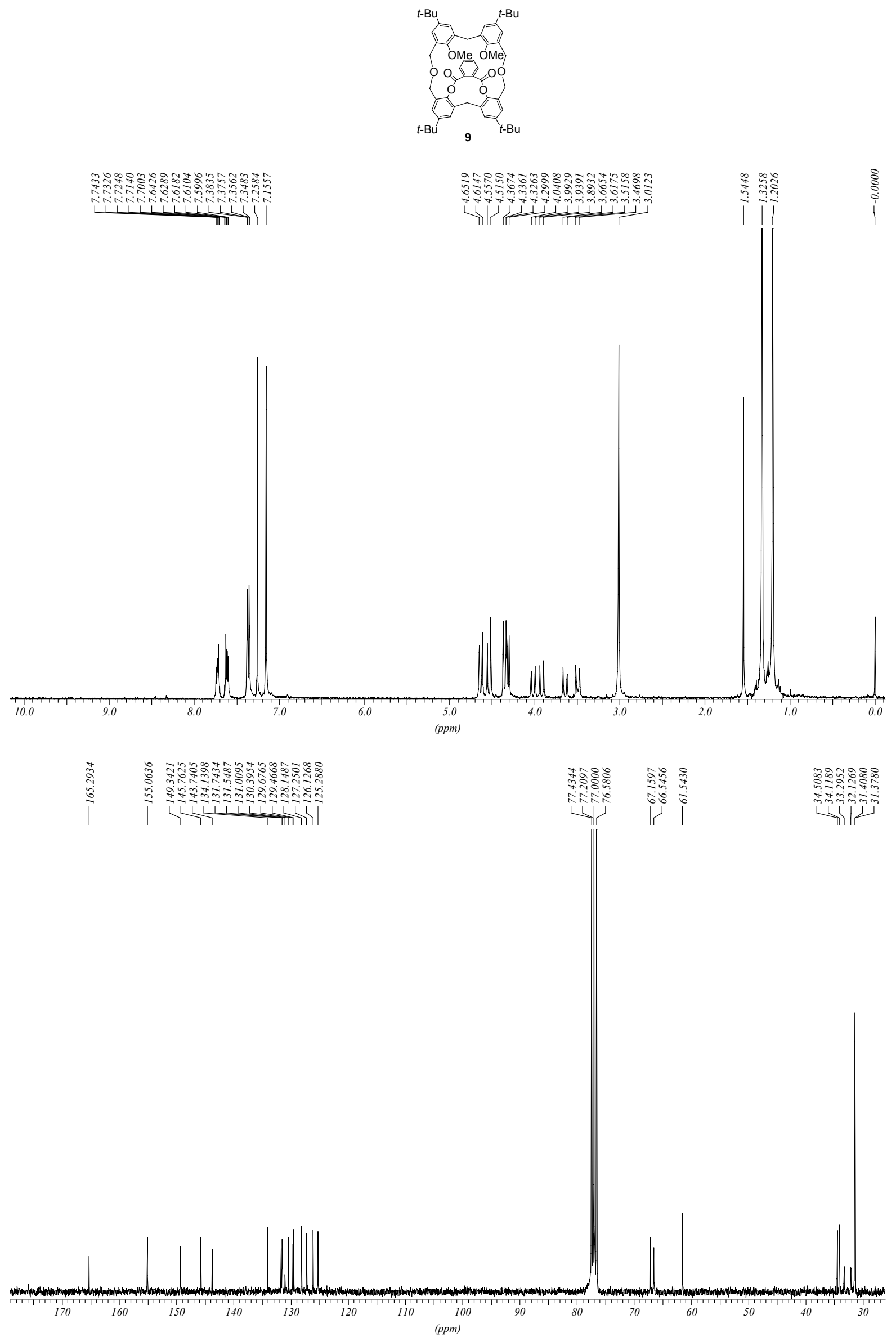

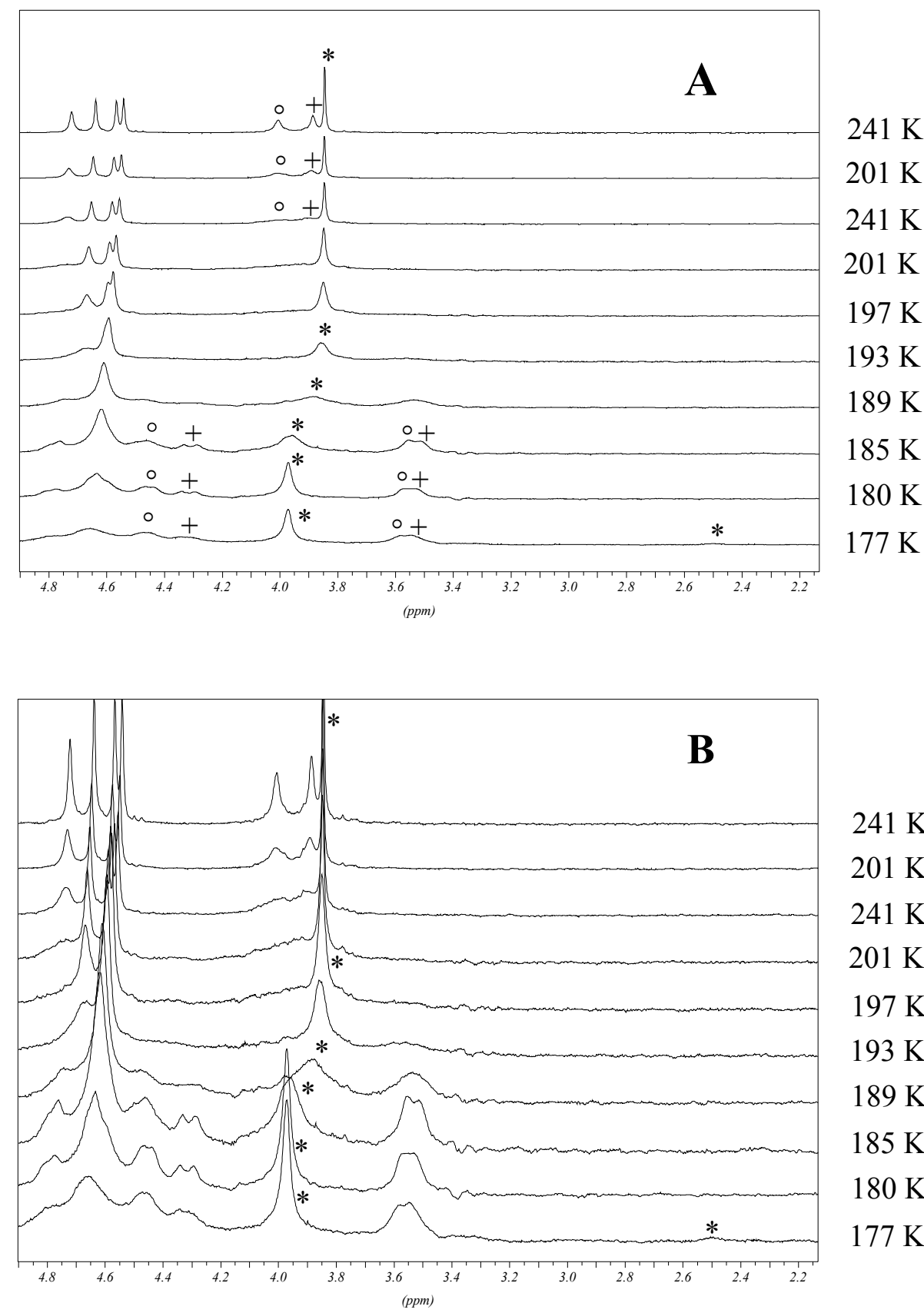

$241 \mathrm{~K}$

$201 \mathrm{~K}$

$241 \mathrm{~K}$

$201 \mathrm{~K}$

$197 \mathrm{~K}$

$193 \mathrm{~K}$

$189 \mathrm{~K}$

$185 \mathrm{~K}$

$180 \mathrm{~K}$

$177 \mathrm{~K}$

FIGURE S1. ${ }^{1} \mathrm{H}$ NMR spectra (central region) of compound 2 at low temperatures, in $\mathrm{CD}_{2} \mathrm{Cl}_{2}$. In $\mathbf{A}$ symbols mark the proposed splitting pattern for the 2 types of $\mathrm{ArCH}_{2} \mathrm{Ar}$ protons $(+)$ and (o), and for the $\mathrm{OCH}_{3}$ protons (*); in $\mathbf{B}$ the spectra are amplified and only $\mathrm{OCH}_{3}$ signals are marked. 


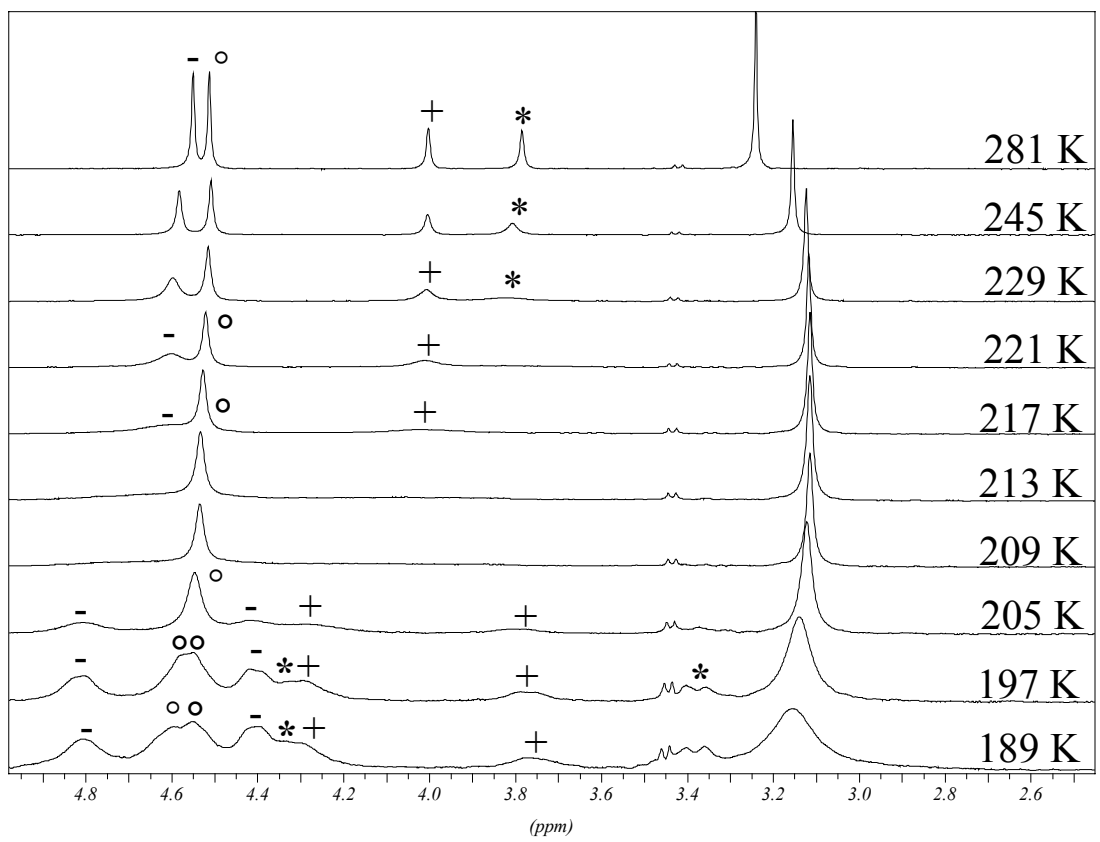

FIGURE S2. ${ }^{1} \mathrm{H}$ NMR spectra (central region) of compound 3 at low temperatures, in $\mathrm{CD}_{2} \mathrm{Cl}_{2}$. Symbols mark the proposed splitting pattern for 4 types of $\mathrm{CH}_{2}$ signals. No splitting is observed for the $\mathrm{OCH}_{3}$ signal at ca. $3.1 \mathrm{ppm}$. 

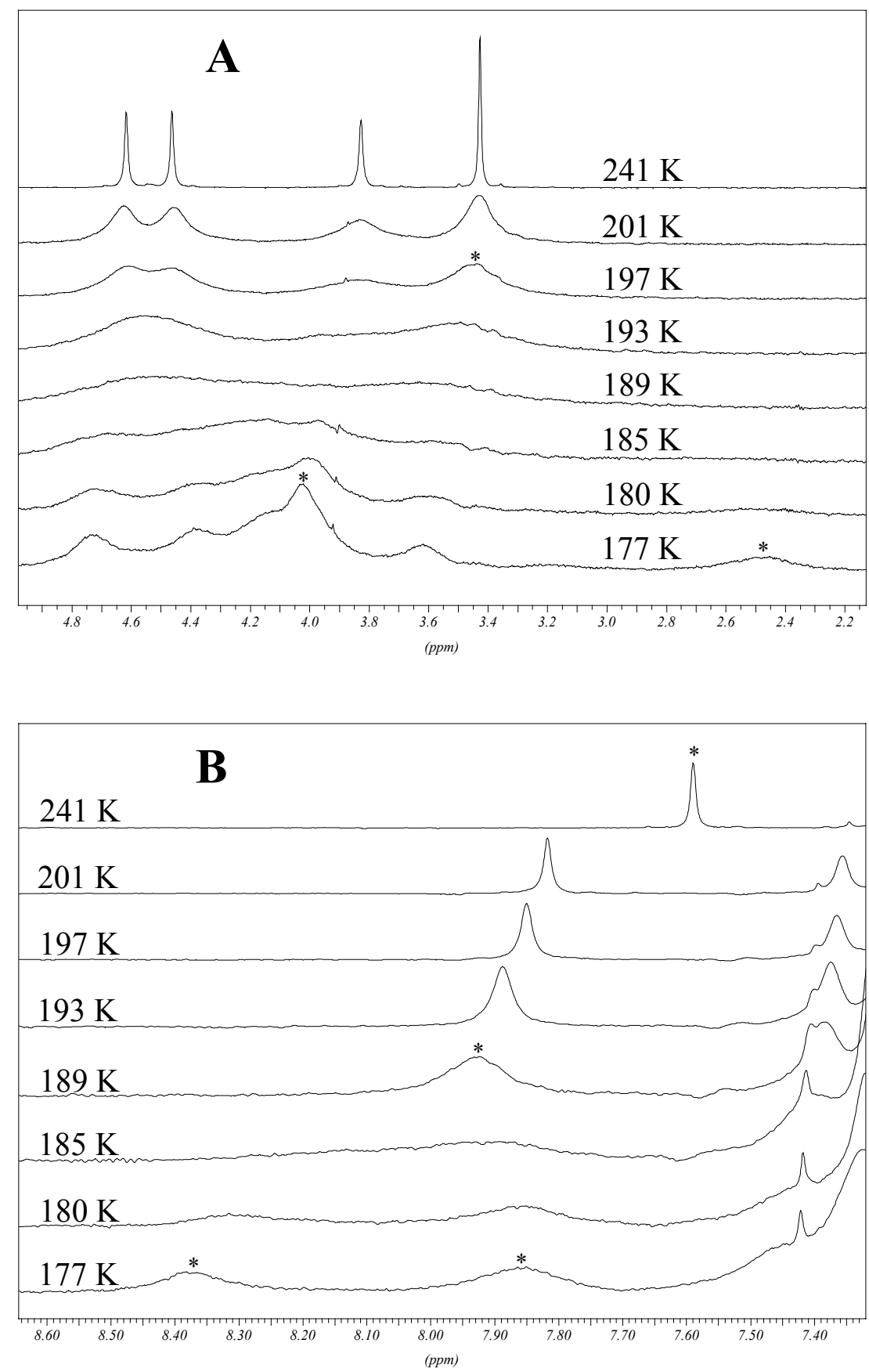

FIGURE S3. ${ }^{1} \mathrm{H}$ NMR spectra of compound 5 at low temperatures, in $\mathrm{CD}_{2} \mathrm{Cl}_{2}$. Proposed splitting pattern for $\mathrm{OCH}_{3}$ protons (A) and $\mathrm{ArOH}$ protons (B). The \% composition of conformations was estimated from the chemical shifts of the starred peaks in the former case and from the areas of the split starred peaks in the latter case. 


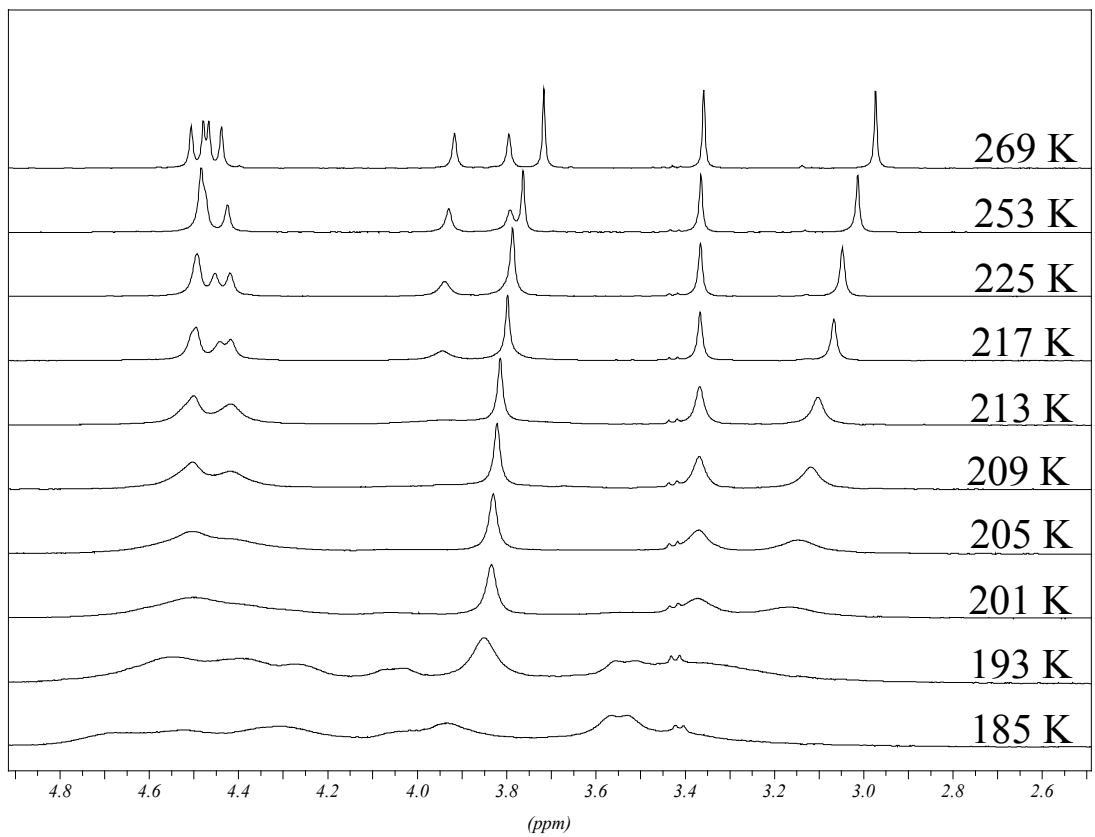

FIGURE S4. ${ }^{1} \mathrm{H}$ NMR spectra (central region) of compound $\mathbf{6}$ at low temperatures, in $\mathrm{CD}_{2} \mathrm{Cl}_{2}$. 


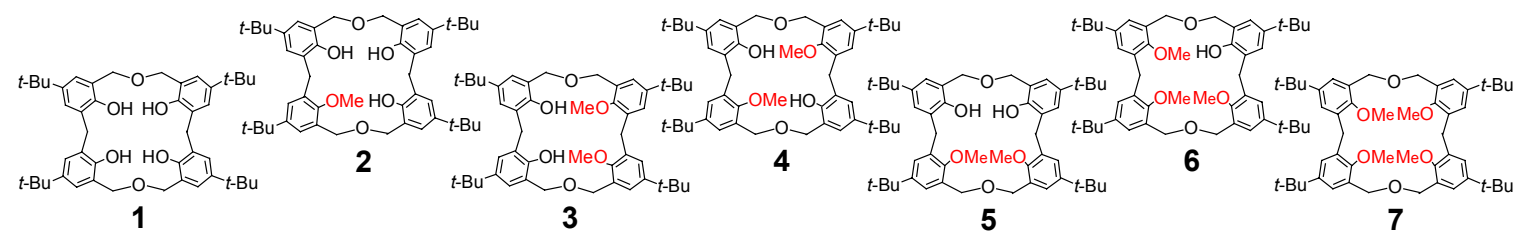

Cone

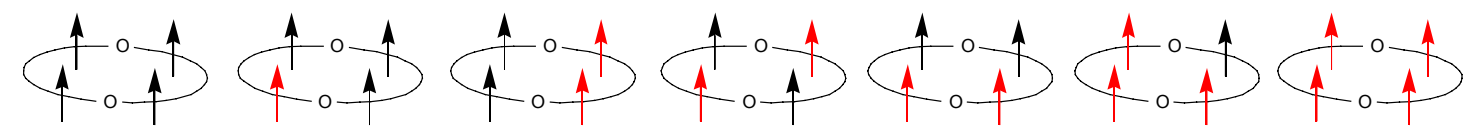

Partial cone

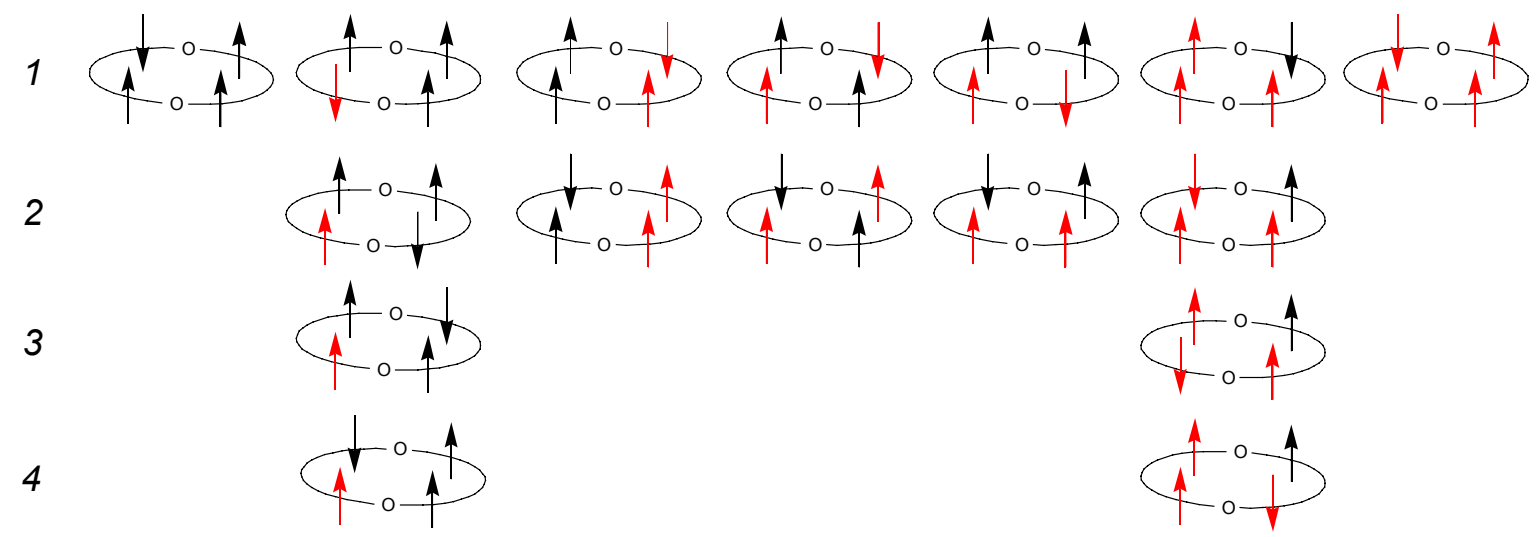

Alternate

$1,2 \underbrace{4}_{0}$
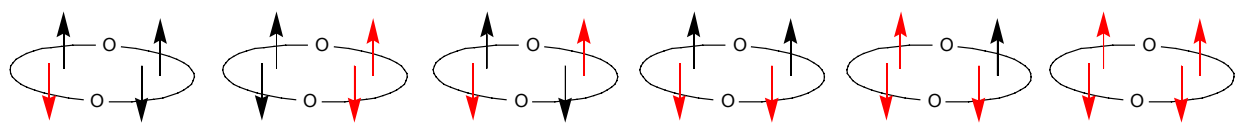

$1,3 \overbrace{\substack{1 \\ \text { f }}}^{1}$
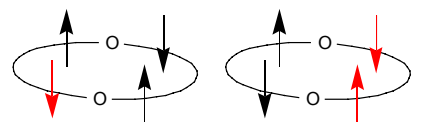

$\operatorname{lip}_{0}^{1} 0$
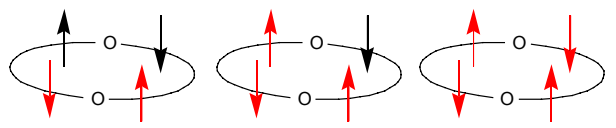

$1,4 \overbrace{0 \rightarrow \uparrow}^{t}$
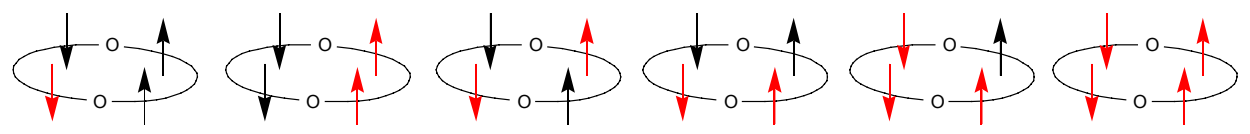

FIGURE S5. Schematic representation of all the ideal conformations of compounds 1-7. 
Crystallographic Data Collection and Structure Determinations. The data were collected at 100(2) $\mathrm{K}$ on a Nonius Kappa-CCD area detector diffractometer ${ }^{1}$ using graphite-monochromated Mo-K $\alpha$ radiation $(\lambda=0.71073 \AA)$. The crystals were introduced in glass capillaries with a protecting "ParatoneN" oil (Hampton Research) coating. The unit cell parameters were determined from ten frames, then refined on all data. A $180^{\circ} \varphi$-range was scanned with $2^{\circ}$ steps during data collection, with additional $\varphi$ and $\omega$-scans if necessary. The data were processed with DENZO and SCALEPACK (HKL2000 package). ${ }^{2}$ The structures were solved by direct methods with SHELXS-97 and subsequent Fourierdifference synthesis and refined by full-matrix least-squares on $F^{2}$ with $S H E L X L-97 .{ }^{3}$ No absorption correction was necessary. All non-hydrogen atoms were refined with anisotropic displacement parameters. Carbon-bound hydrogen atoms were introduced at calculated positions and were treated as riding atoms (as well as the oxygen-bound hydrogen atoms, when found) with a displacement parameter equal to $1.2\left(\mathrm{OH}, \mathrm{CH}, \mathrm{CH}_{2}\right)$ or $1.5\left(\mathrm{CH}_{3}\right)$ times that of the parent atom. Specific details are as follows:

Compound 2. The asymmetric unit comprises two independent half-molecules, denoted A and B, both disordered. In molecule A, the methoxy group is located on O1A and has been affected with a 0.5 occupancy factor, as well as the hydrogen atom bound to O1A, so that there is on average one methoxy and one hydroxy group per molecule. The two tert-butyl groups of this molecule are rotationally disordered over two positions which have been refined with occupancy parameters constrained to sum to unity. In molecule $\mathrm{B}$, the methoxy group is disordered over the two atoms $\mathrm{O} 1 \mathrm{~B}$ and $\mathrm{O} 2 \mathrm{~B}$, both positions having been affected with a 0.25 occupancy factor, and the hydrogen atoms bound to the corresponding oxygen atoms with a 0.75 one. Some restraints on displacement parameters and/or bond lengths were applied for the tert-butyl and methoxy groups. The hydrogen atoms of the hydroxy groups were found on a Fourier-difference map and, in spite of the important disorder, they appear to be correctly located to form hydrogen bonds with neighbouring oxygen atoms. 
Compound $3 \cdot \mathrm{CHCl}_{3} \cdot \mathrm{H}_{2} \mathrm{O} \cdot 0.5 \mathrm{MeOH}$. Three tert-butyl groups were found to be rotationally disordered over two positions which were refined with occupancy parameters constrained to sum to unity. Some restraints on displacement parameters were applied for some badly behaving atoms in the disordered groups and solvent molecules. The hydrogen atoms of the hydroxy groups were found on a Fourierdifference map, but those of the methanol and water solvent molecules were not found, nor introduced.

Compounds 4 and 5. The hydrogen atoms of the hydroxy groups were found on a Fourier-difference map.

Compound 6. As in compound 2, the carbon atom of the methoxy group is disordered over two positions involving $\mathrm{O} 2$ and its image $\mathrm{O} 2$ ' through the inversion center and has thus been affected with a 0.5 occupancy parameter. The disordered hydroxy proton was not found.

Crystal data and structure refinement details are given in Table 1. The molecular plots were drawn with SHELXTL. ${ }^{4}$

(1) Kappa-CCD Software; Nonius B.V.: Delft, The Netherlands, 1998.

(2) Otwinowski, Z.; Minor, W. Methods Enzymol. 1997, 276, 307.

(3) Sheldrick, G. M. SHELXS-97 and SHELXL-97; University of Göttingen, Germany, 1997.

(4) Sheldrick, G. M. SHELXTL, Version 5.1; Bruker AXS Inc.: Madison, WI, USA, 1999 
TABLE S1. Crystal Data and Structure Refinement Details

\begin{tabular}{|c|c|c|c|c|c|c|}
\hline & 2 & $\begin{array}{c}\mathbf{3} \cdot \mathrm{CHCl}_{3} \cdot \mathrm{H}_{2} \mathrm{O} \cdot 0.5 \\
\mathrm{MeOH}\end{array}$ & 4 & 5 & 6 & 7 \\
\hline empirical formula & $\mathrm{C}_{47} \mathrm{H}_{62} \mathrm{O}_{6}$ & $\mathrm{C}_{49.5} \mathrm{H}_{69} \mathrm{Cl}_{3} \mathrm{O}_{7.5}$ & $\mathrm{C}_{48} \mathrm{H}_{64} \mathrm{O}_{6}$ & $\mathrm{C}_{48} \mathrm{H}_{64} \mathrm{O}_{6}$ & $\mathrm{C}_{49} \mathrm{H}_{66} \mathrm{O}_{6}$ & $\mathrm{C}_{50} \mathrm{H}_{68} \mathrm{O}_{6}$ \\
\hline$M / \mathrm{g} \mathrm{mol}^{-1}$ & 722.97 & 890.40 & 736.99 & 736.99 & 751.02 & 765.04 \\
\hline crystal system & monoclinic & triclinic & triclinic & monoclinic & monoclinic & monoclinic \\
\hline space group & $P 2_{1} / n$ & $P \overline{1}$ & $P \overline{1}$ & $P 2_{1} / c$ & $P 2_{1} / n$ & $C 2 / c$ \\
\hline$a / \AA$ & $16.1127(6)$ & $13.5059(5)$ & $6.0627(7)$ & $9.7267(17)$ & $13.5929(12)$ & $30.6685(18)$ \\
\hline$b / \AA$ & $9.9911(6)$ & $20.4824(7)$ & $11.5013(11)$ & $21.884(4)$ & $9.3211(7)$ & $14.3273(5)$ \\
\hline$c / \AA$ & $25.7335(11)$ & 20.9212(9) & $15.322(2)$ & $19.784(3)$ & $17.7157(11)$ & $23.3049(13)$ \\
\hline$\alpha /^{\circ}$ & 90 & $61.890(2)$ & $89.214(7)$ & 90 & 90 & 90 \\
\hline$\beta /{ }^{\circ}$ & $96.862(3)$ & $87.258(2)$ & $81.669(6)$ & $93.650(9)$ & $106.728(5)$ & $117.988(3)$ \\
\hline$\gamma^{\circ}{ }^{\circ}$ & 90 & $89.082(2)$ & $79.155(7)$ & 90 & 90 & 90 \\
\hline$V / \AA^{3}$ & $4113.0(3)$ & $5098.9(4)$ & $1038.1(2)$ & $4202.7(12)$ & $2149.6(3)$ & $9042.5(8)$ \\
\hline$Z$ & 4 & 4 & 1 & 4 & 2 & 8 \\
\hline$D_{\text {cald }} / \mathrm{g} \mathrm{cm}^{-3}$ & 1.168 & 1.160 & 1.179 & 1.165 & 1.160 & 1.124 \\
\hline$\mu(\mathrm{MoK} \alpha) / \mathrm{mm}^{-1}$ & 0.075 & 0.227 & 0.076 & 0.075 & 0.074 & 0.072 \\
\hline$F(000)$ & 1568 & 1908 & 400 & 1600 & 816 & 3328 \\
\hline reflections collected & 31539 & 161520 & 7838 & 28722 & 15405 & 97090 \\
\hline independent reflections & 7650 & 19139 & 3603 & 7851 & 3919 & 8586 \\
\hline observed reflections & 4815 & 14125 & 2627 & 3471 & 2742 & 6146 \\
\hline \multicolumn{7}{|l|}{$[I>2 \sigma(I)]$} \\
\hline$R_{\text {int }}$ & 0.086 & 0.068 & 0.058 & 0.087 & 0.046 & 0.108 \\
\hline parameters refined & 571 & 1250 & 251 & 501 & 261 & 521 \\
\hline$R 1$ & 0.068 & 0.091 & 0.068 & 0.085 & 0.093 & 0.054 \\
\hline$w R 2$ & 0.200 & 0.260 & 0.181 & 0.223 & 0.235 & 0.174 \\
\hline$S$ & 1.051 & 1.073 & 1.048 & 1.033 & 1.036 & 1.019 \\
\hline$\Delta \rho_{\min } / \mathrm{e} \AA^{-3}$ & -0.29 & -0.88 & -0.23 & -0.27 & -0.39 & -0.24 \\
\hline$\Delta \rho_{\max } / \mathrm{e} \AA^{-3}$ & 0.40 & 1.65 & 0.34 & 0.30 & 0.90 & 0.27 \\
\hline
\end{tabular}

